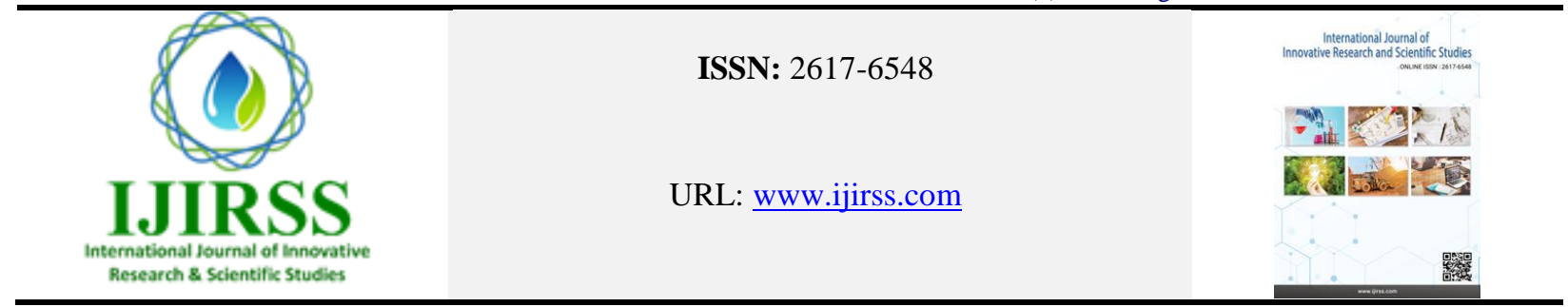

\title{
Assessing the Role of Media in Crisis Management in Afghanistan: A Case Study of Crisis Caused by Coronavirus Outbreak
}

\author{
Muhammad Ragheb Eftikhari \\ Department of Journalism, Social Sciences Faculty, Jawzjan University, Jawzjan, Afghanistan \\ (Email: najiakarimi1986@gmail.com)
}

\begin{abstract}
This study evaluated the relationship between media use and citizens' awareness of coronavirus. The method of this research was quantitative-survey, and the data collection tool was a questionnaire. The sample size was 383 people and determined using the Cochran's formula. The questionnaire was distributed online and conducted within 30 days from the $3^{\text {rd }}$ April to the $3^{\text {rd }}$ May of 2020. SPSS software was used to analyze the data. The statistical population of the study was Facebook users. In the present study, the independent variable was media use and the dependent variable was the level of public awareness in three dimensions; awareness, speed of information and fading of traditional beliefs have been measured. Findings showed that the media, especially Facebook, due to the characteristics of availability, decentralization, time and frequency, as well as the role of awareness and information in crisis control and management has been impressed in Afghanistan. Based on the results, the first and second hypotheses of the research that there is a relationship between access to media and high level of awareness as well as the relationship between access to media and increasing the speed of information are confirmed, but the third hypothesis due to the low intensity of the relationship between its variables was somewhat ruled out.
\end{abstract}

Keywords: Media, Facebook, Crisis Management, Coronavirus.

DOI: $10.53894 /$ ijirss.v3i4.43

Funding: This study received no specific financial support.

History: Received: 1 August 2020/Revised: 1 October 2020/Accepted: 13 October 2020/Published: 30 October 2020

Licensed: This work is licensed under a Creative Commons Attribution 4.0 License (cc) Er

Competing Interests: The author declares that there are no conflicts of interests regarding the publication of this paper.

Transparency: The author confirms that the manuscript is an honest, accurate, and transparent account of the study was reported; that no vital features of the study have been omitted; and that any discrepancies from the study as planned have been explained.

Ethical: This study follows all ethical practices during writing. 


\title{
ارزيابى نقش رسانهها در زمينهى مديريت بحران در افغانستان

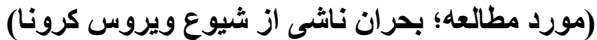

\author{
محمد راغب افتخارى \\ دبيارتمنت ثورناليزم، د/نشكده علوم اجتماعى، دانشكاه جوزجان؛ جوزجان، افغانستان
}

\begin{abstract}
خلاصه

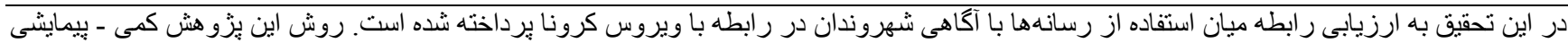

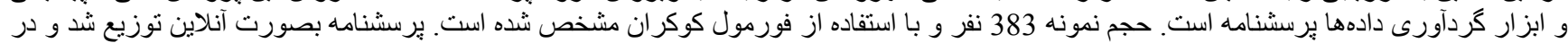

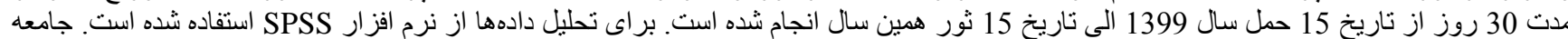

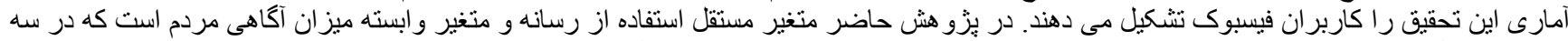

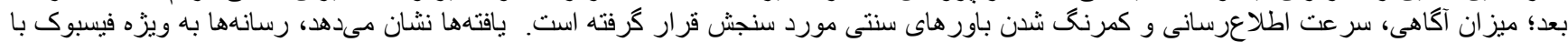

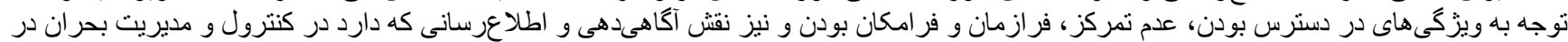

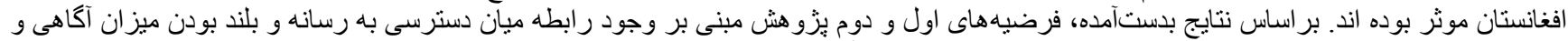

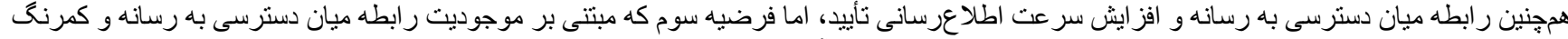

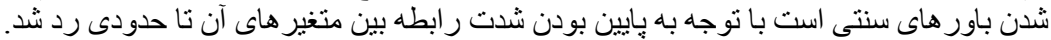

كلمات كليايى: رسانه، فيسبوك، مديريت بحر ان، ويروس كرونا

1

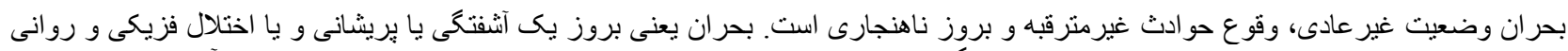

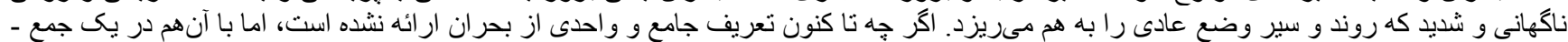

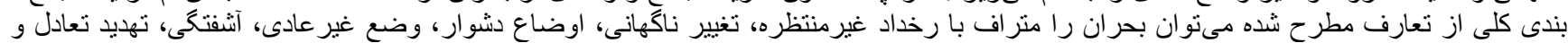

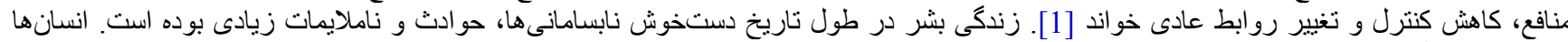

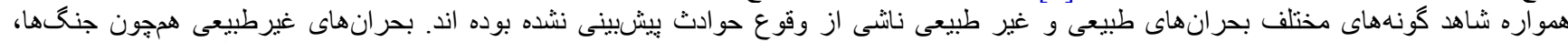

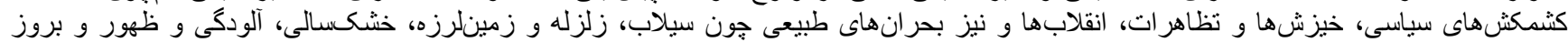

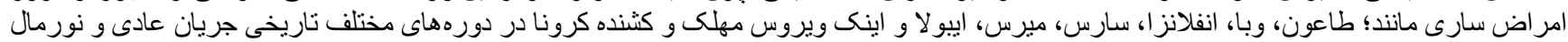

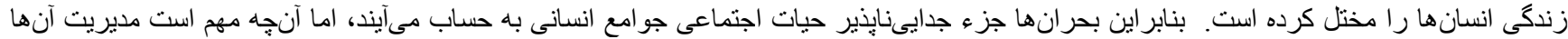

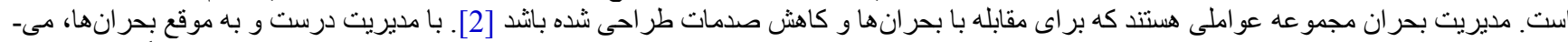

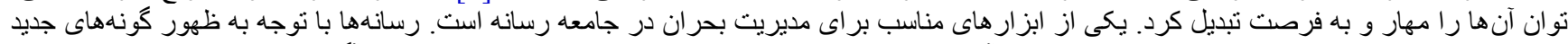

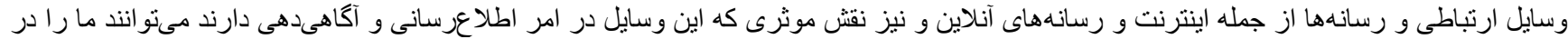

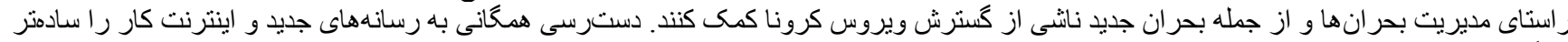

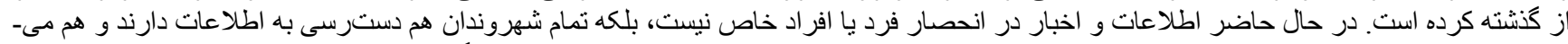

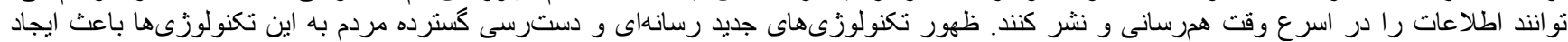

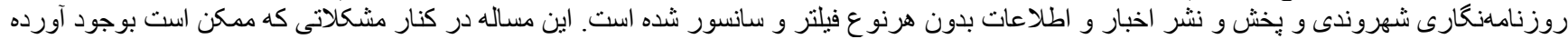

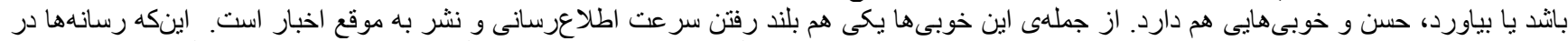

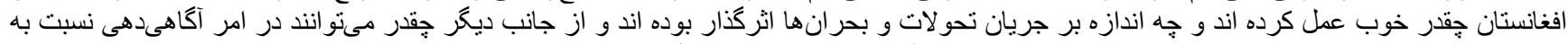

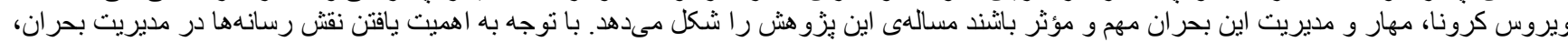

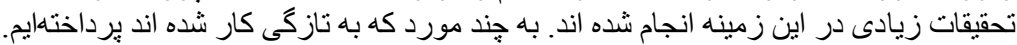

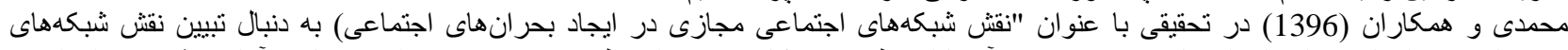

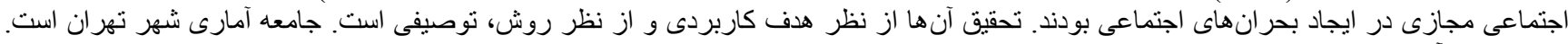

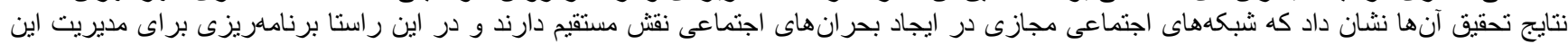

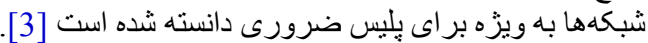

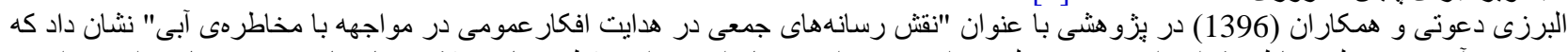

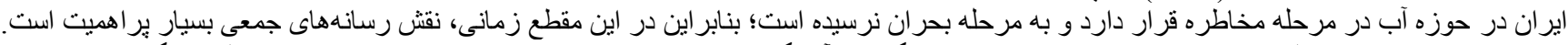

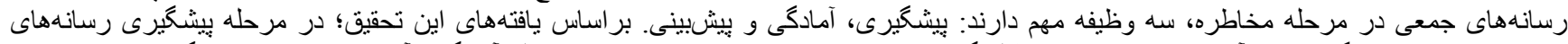

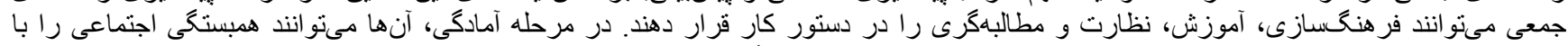

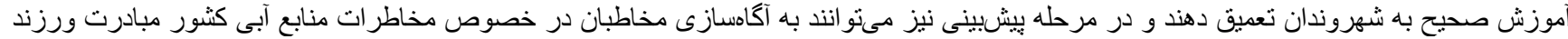

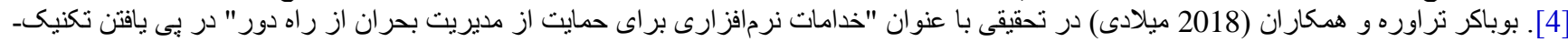

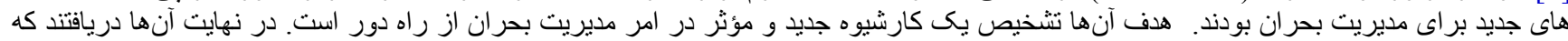

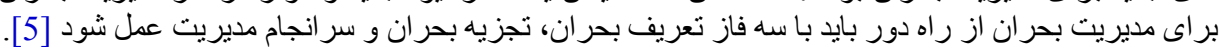

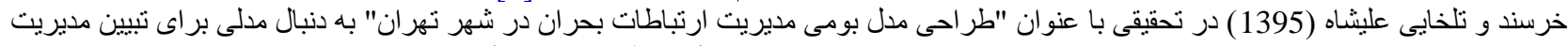

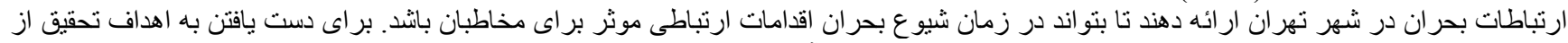

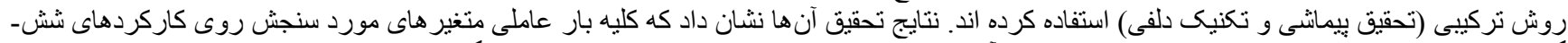

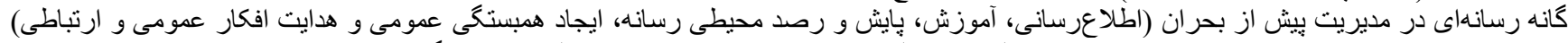

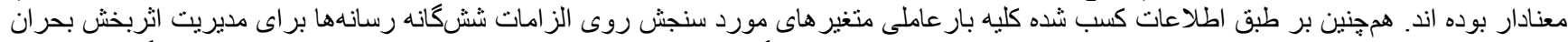

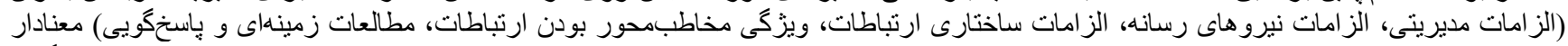

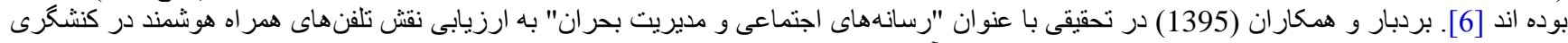

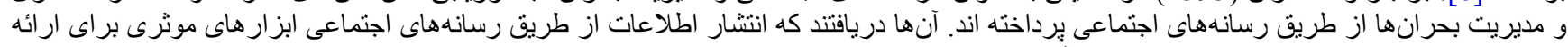

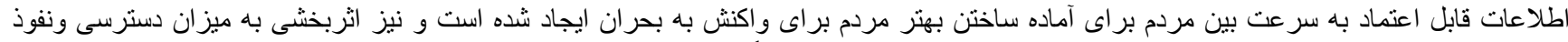

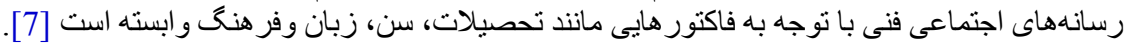




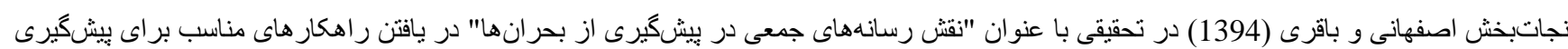

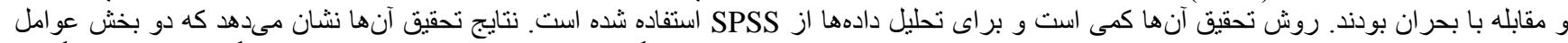

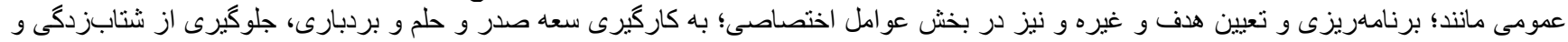

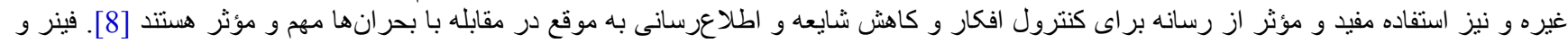

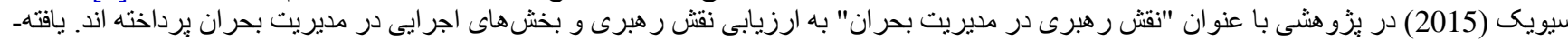

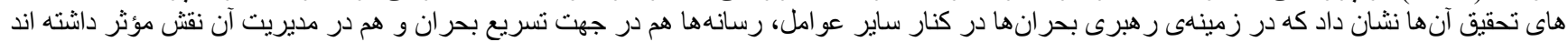

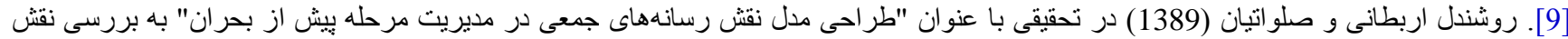

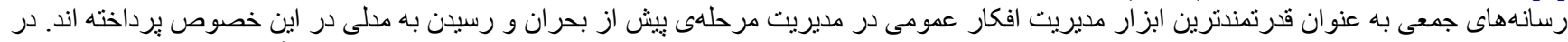

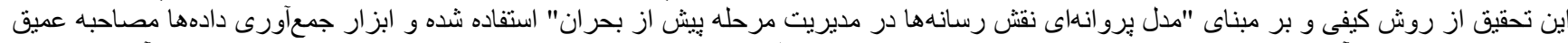

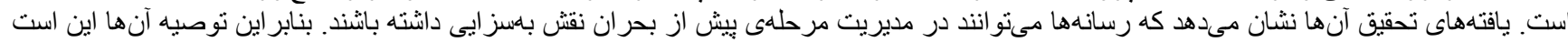

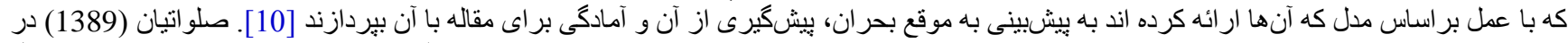

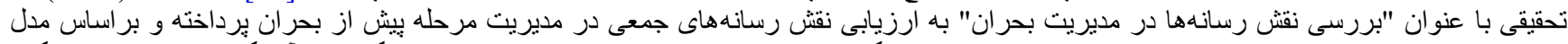

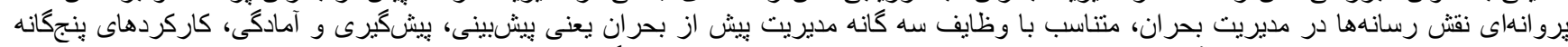

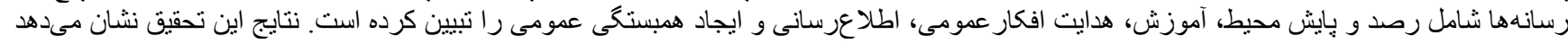

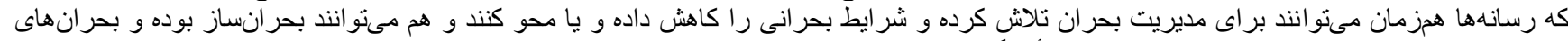

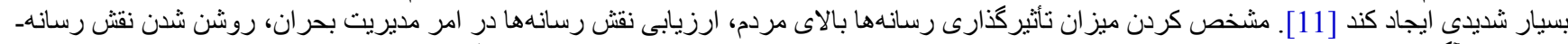

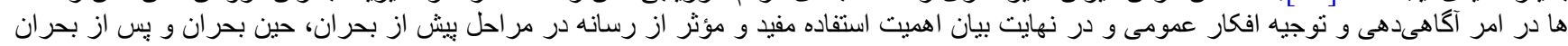
اهداف اين بزّو هش را شكل مىدهند.

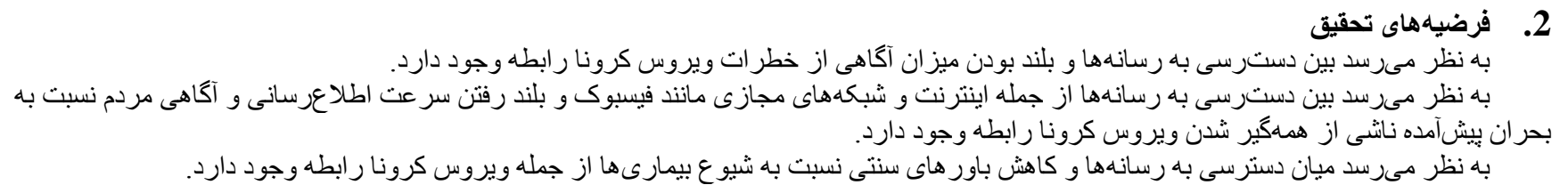

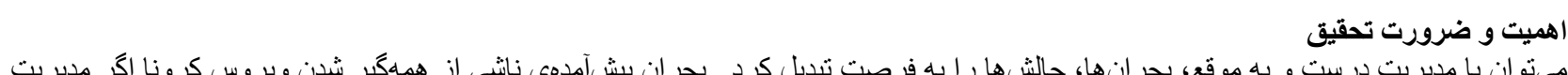

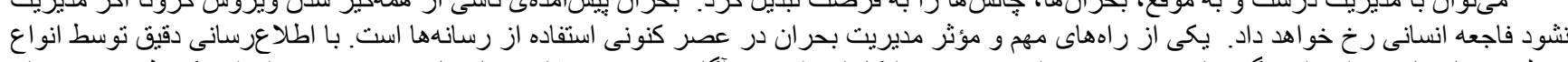

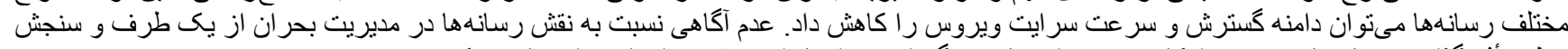

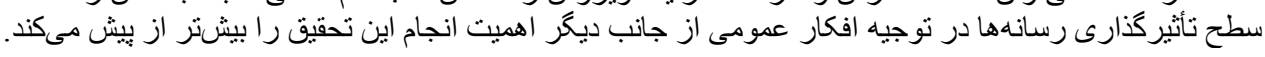

1.3

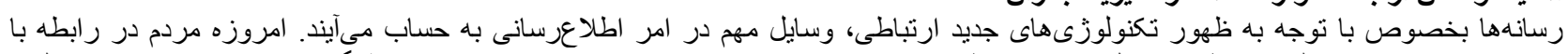

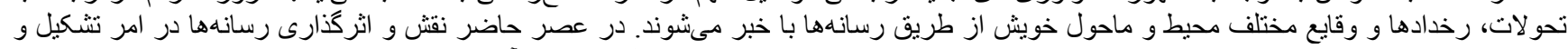

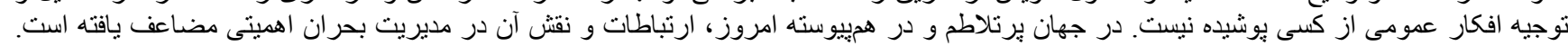

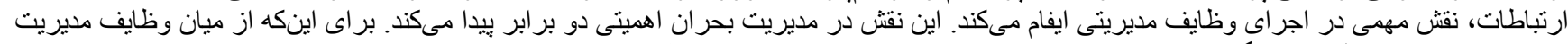

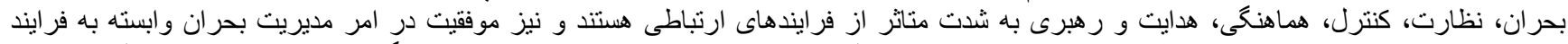

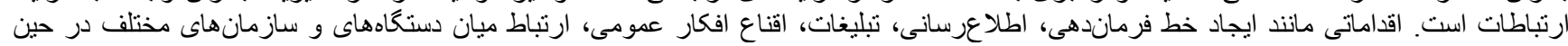

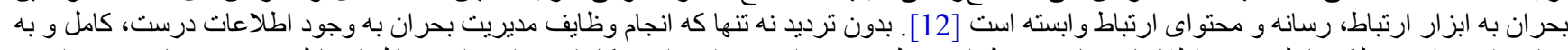

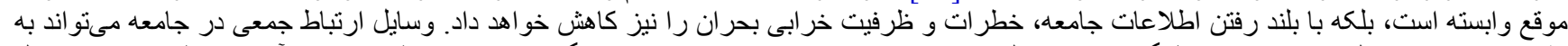

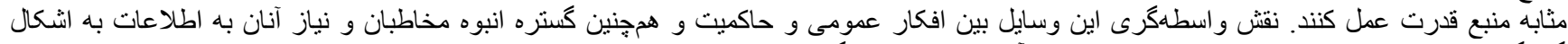

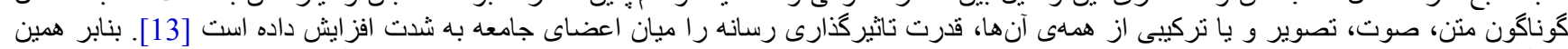

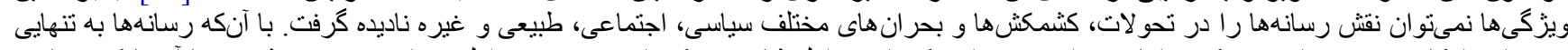

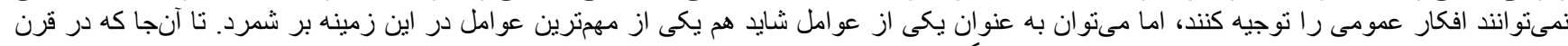

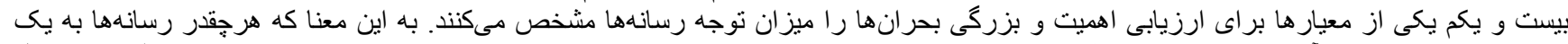

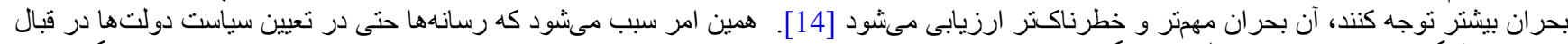

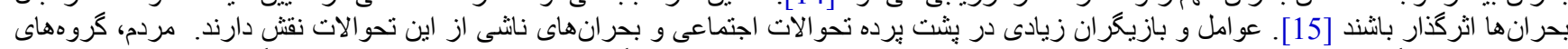

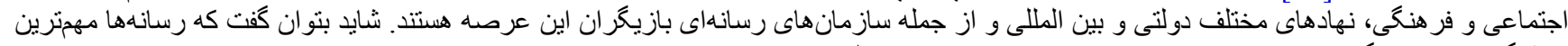

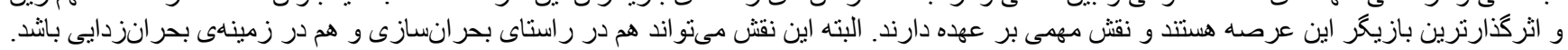

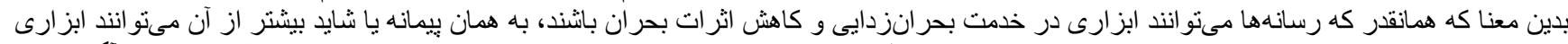

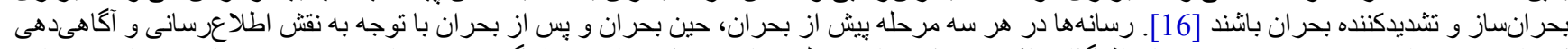

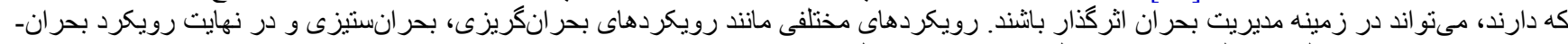

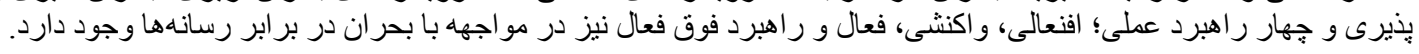

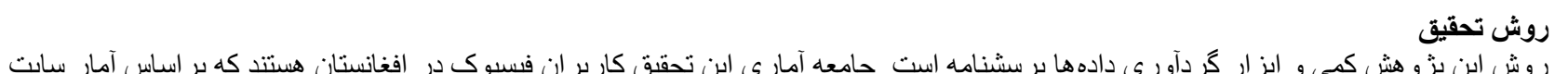

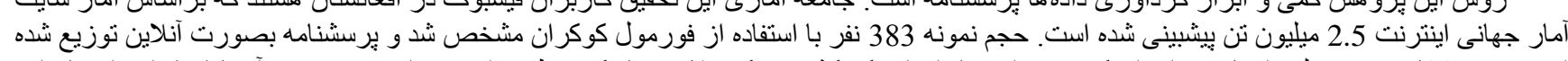

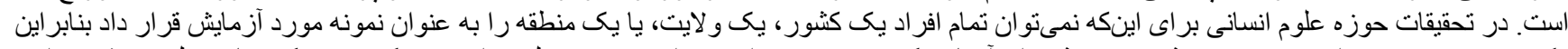

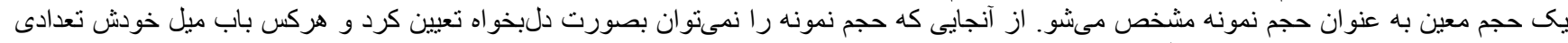

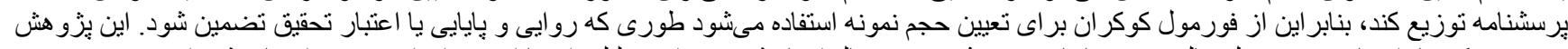

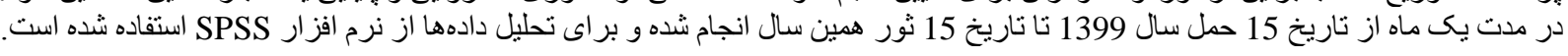


5 الفـ مشخصات باستخَّويان

1.5

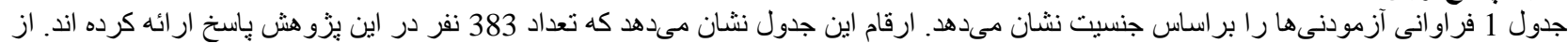

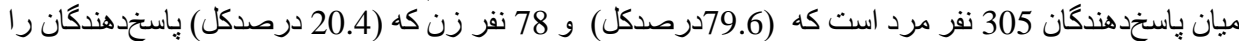

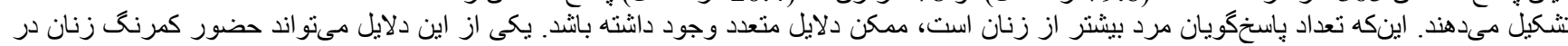

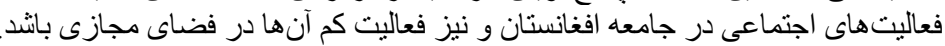

\begin{tabular}{|c|c|c|c|c|c|}
\hline $\begin{array}{c}\text { Cumulative } \\
\text { Percent }\end{array}$ & $\begin{array}{c}\text { Valid } \\
\text { Percent }\end{array}$ & Percent & Frequency & & \\
\hline 79.6 & 79.6 & 79.6 & 305 & مرد & \\
\hline \multirow[t]{2}{*}{100} & 20.4 & 20.4 & 78 & زن & Valid \\
\hline & 100 & 100 & 383 & Total & \\
\hline
\end{tabular}

2.5

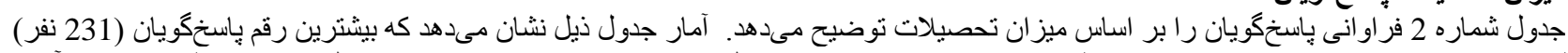

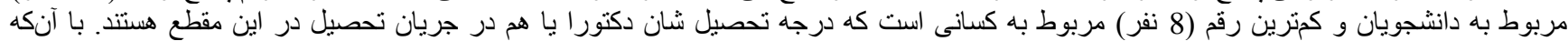

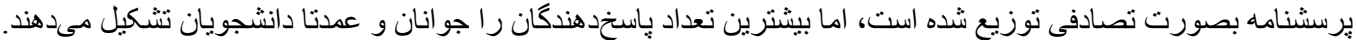

\begin{tabular}{|c|c|c|c|c|c|}
\hline & & Frequency & Percent & Valid Percent & Cumulative Percent \\
\hline \multirow{5}{*}{ Valid } & متعلم & 46 & 12.0 & 12.0 & 12.0 \\
\hline & دانشجو & 231 & 60.3 & 60.3 & 72.3 \\
\hline & ليسانس و ماستر & 98 & 25.6 & 25.6 & 97.9 \\
\hline & دكتور & 8 & 2.1 & 2.1 & 100.0 \\
\hline & Total & 383 & 100.0 & 100.0 & \\
\hline
\end{tabular}

3.5

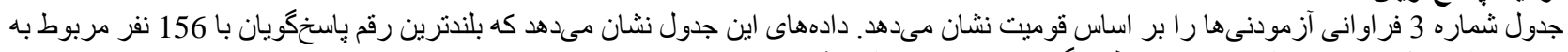

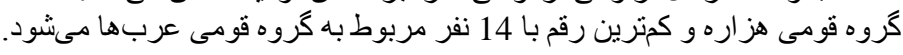

جدول 3: فراو انى آزمودنىها را بر اساس قوميت.

\begin{tabular}{|c|c|c|c|c|c|}
\hline & & Frequency & Percent & Valid Percent & Cumulative Percent \\
\hline \multirow{9}{*}{ Valid } & ت تاجيك & 47 & 12.3 & 12.3 & 12.3 \\
\hline & هزاره & 156 & 40.7 & 40.7 & 53.0 \\
\hline & بلوج & 28 & 7.3 & 7.3 & 60.3 \\
\hline & اوزبيك & 64 & 16.7 & 16.7 & 77.0 \\
\hline & عرب & 14 & 3.7 & 3.7 & 80.7 \\
\hline & بشتون & 40 & 10.4 & 10.4 & 91.1 \\
\hline & سادات & 18 & 4.7 & 4.7 & 95.8 \\
\hline & تركمن & 16 & 4.2 & 4.2 & 100.0 \\
\hline & Total & 383 & 100.0 & 100.0 & \\
\hline
\end{tabular}

4.5

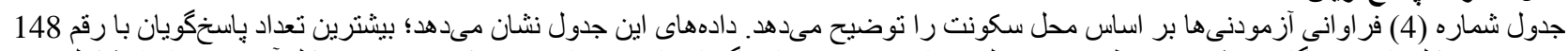

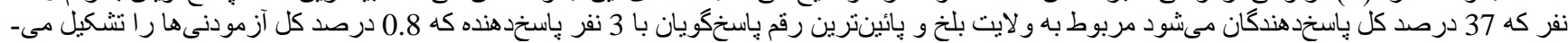

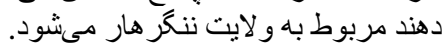

ب- آزمون فرضيات

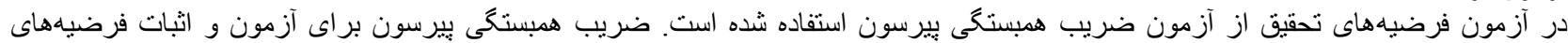

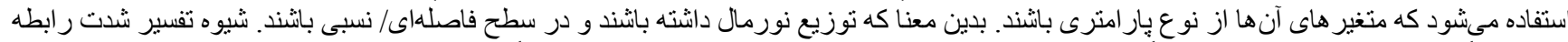

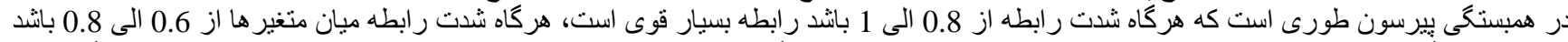

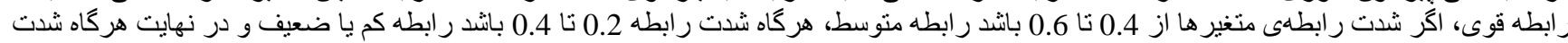

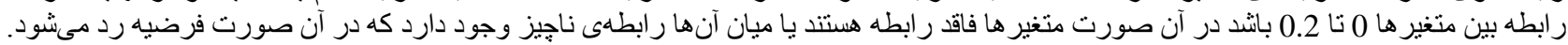




\begin{tabular}{|c|c|c|c|c|c|}
\hline \multicolumn{6}{|c|}{ جدول 4: فر } \\
\hline & & Frequency & Percent & Valid Percent & Cumulative Percent \\
\hline \multirow{16}{*}{ Valid } & كابل & 45 & 11.7 & 11.7 & 11.7 \\
\hline & بلخ & 148 & 38.6 & 38.6 & 50.4 \\
\hline & جوزجان & 59 & 15.4 & 15.4 & 65.8 \\
\hline & تخار & 19 & 5.0 & 5.0 & 70.8 \\
\hline & فارياب & 17 & 4.4 & 4.4 & 75.2 \\
\hline & بغلان & 12 & 3.1 & 3.1 & 78.3 \\
\hline & غزنى & 15 & 3.9 & 3.9 & 82.2 \\
\hline & سنغان & 34 & 8.9 & 8.9 & 91.1 \\
\hline & هرات & 7 & 1.8 & 1.8 & 93.0 \\
\hline & باميان & 4 & 1.0 & 1.0 & 94.0 \\
\hline & دايكندى & 4 & 1.0 & 1.0 & 95.0 \\
\hline & سريل & 4 & 1.0 & 1.0 & 96.1 \\
\hline & كندز & 8 & 2.1 & 2.1 & 98.2 \\
\hline & قتلهار & 4 & 1.0 & 1.0 & 99.2 \\
\hline & ن ن نكرهار & 3 & 0.8 & 0.8 & 100.0 \\
\hline & Total & 383 & 100.0 & 100.0 & \\
\hline
\end{tabular}

\begin{tabular}{|c|c|c|c|}
\hline & 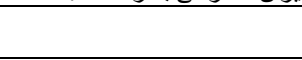 & آكاهى از كرونـا & ميزان دسترسى به رسانهها \\
\hline \multirow{3}{*}{ آكاهى از كرونـا } & Pearson Correlation & 1 &.$/ 86$ \\
\hline & Sig. (2-tailed) & &.$/ 027$ \\
\hline & $\mathrm{N}$ & 383 & 383 \\
\hline \multirow{3}{*}{ ميزان دسترسى به رسانهها } & Pearson Correlation &.$/ 86$ & 1 \\
\hline & Sig. (2-tailed) &.$/ 027$ & \\
\hline & $\mathrm{N}$ & 383 & 383 \\
\hline
\end{tabular}

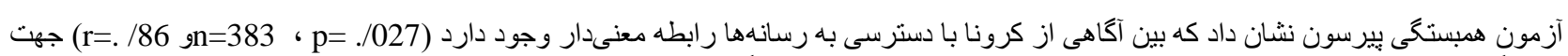

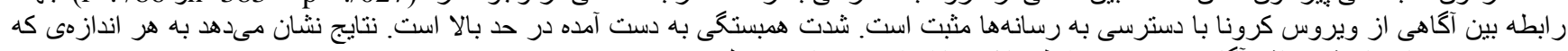

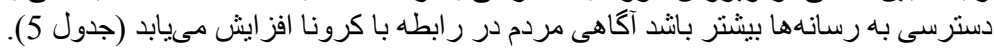

\begin{tabular}{|c|c|c|c|}
\hline & 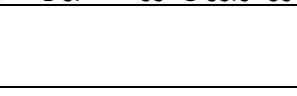 & افزايش اطلاع رسانى در مورد كرونـا & ميزان دسترسنى بهاه \\
\hline \multirow{3}{*}{ افزايش سرعت اطلاعرسانى در } & Pearson Correlation & 1 &.$/ 78$ \\
\hline & Sig. (2-tailed) & &.$/ 036$ \\
\hline & $\mathrm{N}$ & 383 & 383 \\
\hline \multirow{3}{*}{ ميزان دسترسى به رسانهها } & Pearson Correlation &.$/ 78$ & 1 \\
\hline & Sig. (2-tailed) &.$/ 036$ & \\
\hline & $\mathrm{N}$ & 383 & 383 \\
\hline
\end{tabular}

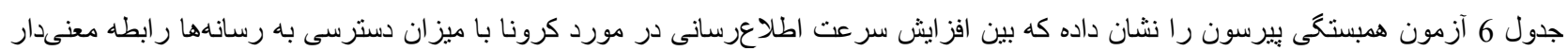

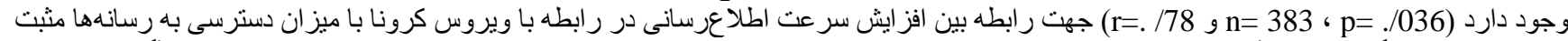

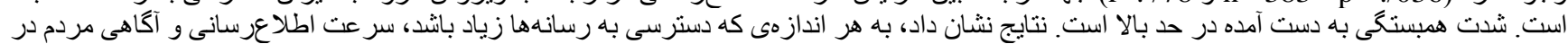

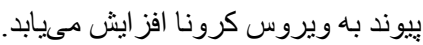

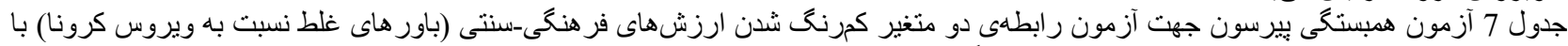

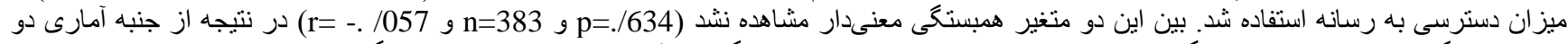

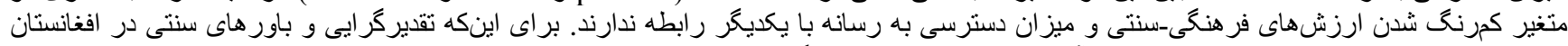

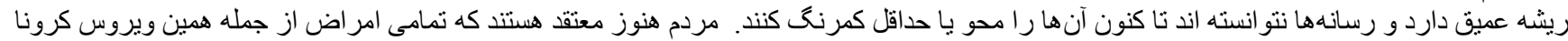

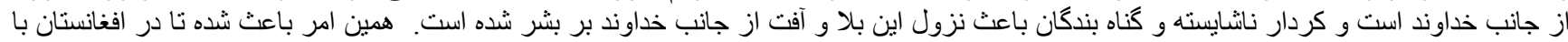

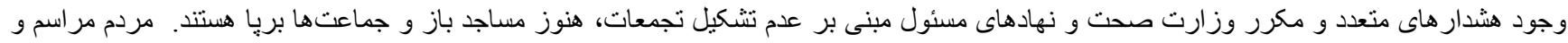




\begin{tabular}{|c|c|c|c|}
\hline \multicolumn{4}{|c|}{ 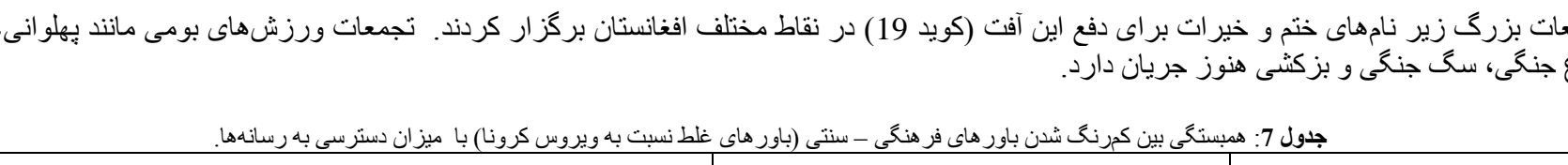 } \\
\hline \multirow{4}{*}{ كررنگ شندن ارزشى سهنى } & & كمرنح شدن ارزش هاى فرهنى ـسنتى & ميزان دسترسى به رسانهها \\
\hline & Pearson Correlation & 1 &.$- / 057$ \\
\hline & Sig. (2-tailed) & &.$/ 634$ \\
\hline & $\mathrm{N}$ & 383 & 383 \\
\hline \multirow{3}{*}{ ميزان دسترسى به رسانه ها } & Pearson Correlation &.$- / 057$ & 1 \\
\hline & Sig. (2-tailed) & .634 & \\
\hline & $\mathrm{N}$ & 383 & 383 \\
\hline
\end{tabular}

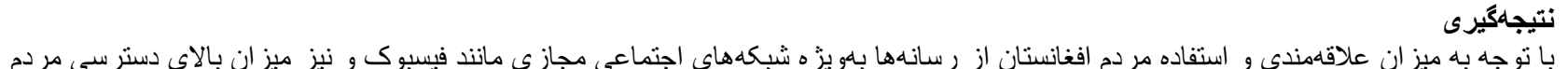

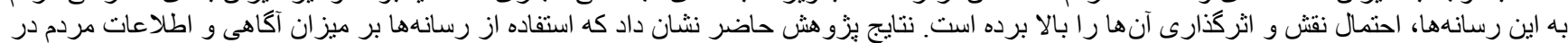

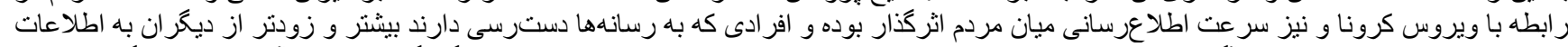

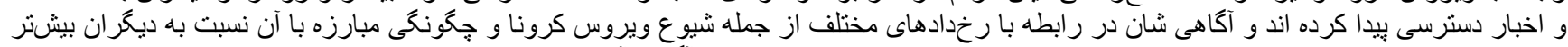

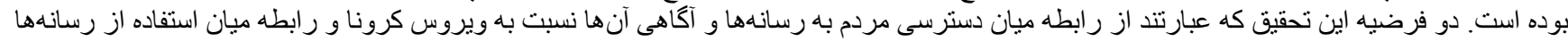

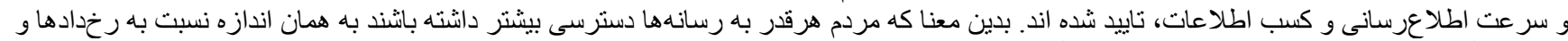

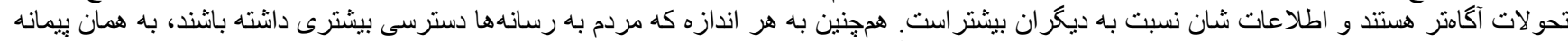

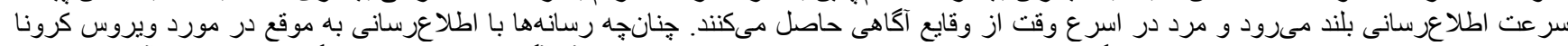

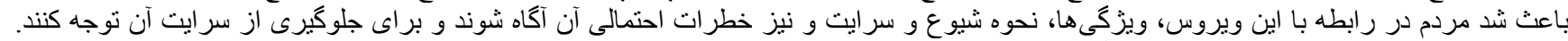

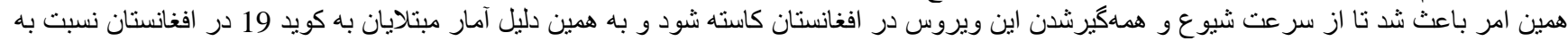

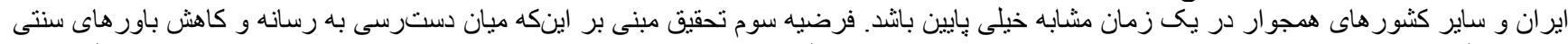

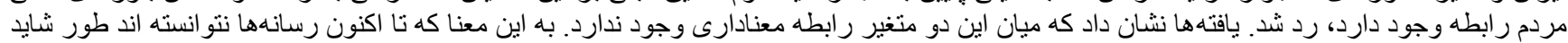

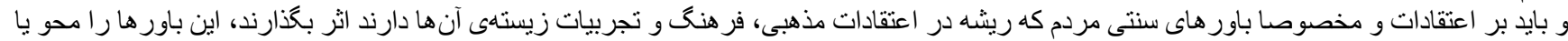

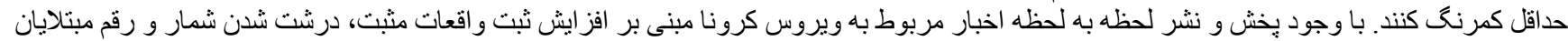

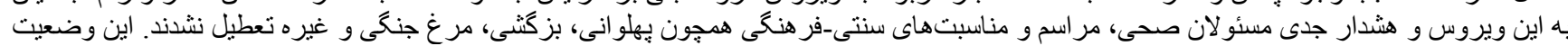

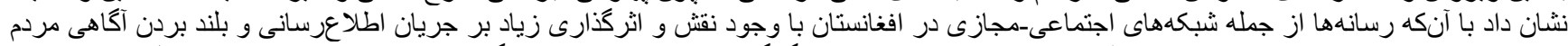

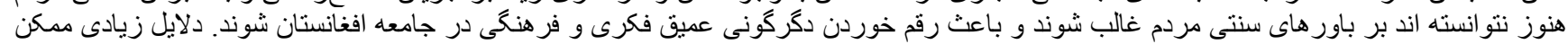

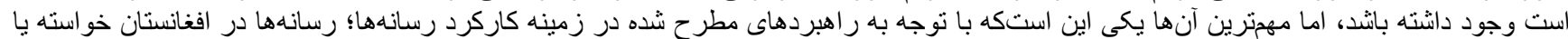

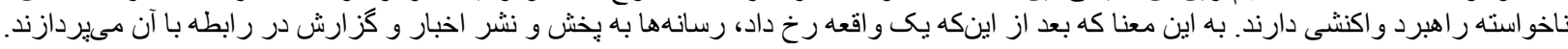

\section{References}

[1] Nasrollahi, Crisis news coverage management. Tehran: Office of Media Studies and Planning, 1392.

[2] W. Coombs and J. Timothy, Haldi, crisis communication. Tehran: Fars News Agency Publications, 1392.

[3] A. Mohammadi, "Yavari et al. Javanmard, The role of virtual social networks in creating social crises," pp. 3-23, 1396.

[4] A. Alborzi Invitation, "Samardepi, the role of mass media in guiding public opinion in the face of water risk," Environmental Risk Management, pp. 367-381, 1396.

[5] B. B. Traore, B. Kamsu-Foguem, F. Tangara, and P. Tiako, "Software services for supporting remote crisis management," Sustainable Cities and Society, vol. 39, pp. 814-827, 2018. Available at: https://doi.org/10.1016/j.scs.2018.02.029.

[6] Khorsand, "Designing a native model of crisis communication management in Tehran," Sociological Studies, pp. 91-107, 1395.

[7] H. Bordbar, J. Basrian, and M. Abdolhosseini, "Social media and crisis management," The Role of Smart Phones in Social Activism, Media, pp. 57-83, 1395.

[8] Esfahani and Bagheri, "The role of mass media in preventing crises," Communication Research, pp. 138-158, 1387.

[9] T. Fener and T. Cevik, "Leadership in crisis management: Separation of leadership and executive concepts," Procedia Economics and Finance, vol. 26, pp. 695-701, 2015. Available at: https://doi.org/10.1016/s2212-5671(15)00817-5.

[10] A. Roshandel, "Salavatian, designing a model for the role of mass media in pre-crisis management," Iranian Management Sciences, pp. 1-24, 1389.

[11] S. Salavatian, "Examining the role of media in crisis management with emphasis on three tasks; prediction, prevention and preparedness," ed: Imam Sadegh University Press, 1389, pp. 1-29.

[12] H. Sadat, Crisis management. Tehran: Tisa, 1392.

[13] Wardinejad and R. Bahrami, Crisis management and media. Tehran: Samat Publications, 1389.

[14] S. D. Moeller, "Regarding the pain of others: Media, bias and the coverage of international desasters," Journal of International Affaires, vol. 59, pp. 173-196, 2006.

[15] M. D. Barnes, C. L. Hanson, L. M. Novilla, A. T. Meacham, E. McIntyre, and B. C. Erickson, "Analysis of media agenda setting during and after Hurricane Katrina: Implications for emergency preparedness, disaster response, and disaster policy," American Journal of Public Health, vol. 98, pp. 604-610, 2008.

[16] Arbatani, "The role of media management in the transformation of crisis from threat to opportunity," Journal of Communication Research, vol. 15, pp. 141-163, 1387. 